\section{РАЗРАБОТКА РАЗДЕЛА БИЗНЕС-ПРОЦЕССОВ СБАЛАНСИРОВАННОЙ СИСТЕМЫ ПОКАЗАТЕЛЕЙ АО «КОНЦЕРН РОСЭНЕРГОАТОМ»}

\begin{abstract}
Аннотация:
Статья посвящена вопросу разработки раздела бизнес-процессов сбалансированной системы показателей $A O$ «Концерн Росэнергоатом». Данный раздел сбалансированной системы показателей рассматривается в качестве инструмента, позволяющего осуществлять мониторине, контроллина и планирование деятельности по обеспечению экономической безопасности предприятия. Обозначены различия между традиционной систе мой управления и сбалансированной системой показателей безопасности.
\end{abstract}

Ключевые слова:

экономическая безопасность, АО «Концерн Росэнергоатом», сбалансированная система показателей, стратегия безопасности, бизнес-процесс, стратегическая цель, угроза, риск.

\section{DEVELOPMENT OF THE BALANCED SCORECARD BUSINESS-PROCESS SECTION OF "ROSENERGOATOM CONCERN" OJSC}

Summary:

The article deals with the development of the balanced scorecard business-process section of "Rosenergoatom Concern" OJSC. This section discusses the balanced scorecard as an instrument for monitoring, controlling and planning to ensure economic security of the enterprise. The author markes the differences between the traditional management system and the balanced scorecard of security.

Keywords: economic security, "Rosenergoatom Concern" OJSC, balanced scorecard, safety strategy, business-process, strategic goal, threat, risk.

В современных экономических условиях хозяйствования, которым присущи нестабильность и многоаспектность, важность реализации стратегии экономической безопасности не может быть переоценена, особенно когда речь идет о такой специфической в части рисков отрасли, как атомная.

В ходе диагностики кризисных ситуаций компаний отрасли необходимо в процессе стратегического планирования на этапе анализа сложившегося состояния и прогноза развития выявить наиболее вероятные угрозы (риски) экономической безопасности предприятия, направленность и характер их действия. Это требует непрерывного мониторинга факторов, которые вызывают внутренние и внешние угрозы экономической безопасности.

В ходе данного процесса необходимо анализировать деятельность компании как целостного образования. Отсюда следует, что мониторинг вышеуказанных фракторов следует осуществлять при помощи набора коэффициентов, сведя их количество к необходимому и достаточному значению и произведя их группировку по основным видам деятельности компании [1, с. 744-745].

Удобным инструментом управления, позволяющим осуществлять подобный комплексный мониторинг, является сбалансированная система показателей (ССП). ССП переводит общее видение и стратегию компании в цели и задачи с помощью сбалансированного набора составляющих. Сбалансированная система показателей - это параметры достижения желаемых результатов и процессов.

Традиционно ССП включает в себя следующие составляющие:

- фринансовую;

- клиентскую;

- бизнес-процессов;

- обучения и развития [2, р. 24-29].

Коэффициенты раздела бизнес-процессов ССП ориентированы на достижение таких стратегических целей организации, как уменьшение издержек, нивелирование рисков снижения генерации электрической энергии, рисков ядерной, радиационной, технической, пожарной и экологической безопасности [3].

Вышеуказанные показатели должны быть нацелены на достижение целей предприятия, которые обозначаются в ходе формирования клиентской и финансовой составляющих. Как пра- 
вило, коэффицциенты раздела бизнес-процессов формируются после того, как разработаны клиентская и фринансовая составляющие. Такая последовательность предоставляет предприятиям возможность ориентировать параметры раздела бизнес-процессов ССП на решение задач в интересах клиентов и акционеров.

Процесс разработки целей и коэффициентов внутренних бизнес-процессов иллюстрирует глубокое различие между сбалансированной системой показателей безопасности и традиционной системой управления. Основное внимание последней направлено на усовершенствование и контроль существующих структурных элементов и центров ответственности. Подобный подход, ориентированный на периодические отчеты об отклонениях и фринансовые показатели, является в известной степени ограниченным. Сегодня многие предприятия выходят за границы системы управления, опирающейся на анализ отклонений от финансовых целевых значений. Они добавляют параметры производительности, временных циклов и качества. Указанная система основана на комплексном подходе и, следовательно, более эффективна. Тем не менее данная система также направлена больше на увеличение эффрективности отдельных структурных подразделений, а не на оттачивание интегрированных бизнес-процессов в целом.

На настоящий момент наличие коэфффициентов перекрестных и интегрированных бизнеспроцессов для большинства предприятий является существенным продвижением по сравнению с существующими системами управления. В ССП цели и коэфффициенты раздела внутренних бизнес-процессов формулируются в соответствии со стратегией, которая направлена на удовлетворение ожиданий и потребностей акционеров и клиентов. Этот подход (сверху вниз, или от общего к частному) выявляет абсолютно новые бизнес-процессы, которые требуется довести до совершенства. В результате предприятие сможет точнее формулировать предложения для потребителей, что позволит:

- создать и сохранить клиентскую базу в целевом сегменте рынка;

- удовлетворить ожидания акционеров относительно высоких финансовых результатов.

Коэффрициенты данной составляющей сфокусированы на оценке внутренних процессов предприятия, от которых в большой степени зависит достижение фринансовых целей и удовлетворение клиентских потребностей.

Раздел внутренних бизнес-процессов ССП безопасности призван выявить два принципиальных различия между традиционной системой управления и ССП с точки зрения оценки хозяйственной деятельности фирмы. При традиционном подходе предпринимается попытка совершенствовать и контролировать уже существующие процессы, причем данный подход может включать временные и качественные критерии. Тем не менее указанная традиционная концепция главным образом нацелена именно на улучшение уже созданных бизнес-процессов. Сбалансированная система показателей формирует совершенно новые процессы, при помощи которых предприятие эфрфективно развивается, выполняет пожелания клиентов и решает финансовые задачи. Например, некая организация принимает решение создать новый бизнес-процесс с целью предвосхищения будущих запросов потребителей или развития нового направления обслуживания. Сбалансированная система показателей безопасности выделяет те процессы, которые играют ключевую роль в реализации стратегии компании, причем часть из них может вообще не использоваться на настоящий момент времени.

Следующее отличие двух подходов заключается в том, что ССП безопасности рассматривает нововведения в качестве неотъемлемой части внутренних бизнес-процессов. Отличительной чертой традиционной концепции выступает предоставление существующих услуг и продуктов существующему потребителю. Явно прослеживается попытка совершенствовать и контролировать имеющиеся операции, создающие короткую стоимостную цепь, которая начинается с момента получения заказа от существующего потребителя на предлагаемую компанией услугу или продукт и завершается предоставлением услуги (доставкой продукта). Таким образом, предприятие создает стоимость (производство, доставка, обслуживание) за более высокую цену, чем получает от продажи.

Первым коэффрициентом раздела бизнес-процессов ССП АО «Концерн Росэнергоатом» считаем целесообразным выбрать коэффицциент использования установленной мощности $(K)$ :

$$
K=\frac{Q D-T_{\Pi \Pi P}}{Q D},
$$

где $T_{\text {ППР }}$ - время, потраченное на планово-предупредительный ремонт, отнесенное к конкретному периоду (в сутках);

$Q D$ - количество дней в отчетном периоде (равняется 365 в случае, если идет рассмотрение годового отчетного периода).

Данный показатель отражает среднюю долю от номинальной фактически выработанной электрической мощности за год. 
Коэффициент использования установленной мощности призван стимулировать менеджеров увеличивать эффрективность планово-предупредительных ремонтов и тем самым способствовать достижению стратегической цели АО «Концерн Росэнергоатом» - «снижению себестоимости продукции и сроков протекания процессов» [4, с. 28].

Вторым коэфффициентом раздела бизнес-процессов ССП АО «Концерн Росэнергоатом» следует назначить среднюю электрическую мощность, выработанную на всех АЭС предприятия в отчетном периоде. Данный показатель позволит в абсолютных величинах индицировать эф-фективность реализации стратегической цели по освоению новых рынков.

Третьим коэффициентом составляющей бизнес-процессов ССП целесообразно выбрать расходы на НИОКР, отнесенные к общему объему продаж RIM (Research Intensity Metric). Данный коэффициент позволит привлечь внимание менеджеров к инновациям, которые являются критическим показателем с точки зрения обеспечения экономической безопасности концерна в длительной перспективе:

где $C_{\text {ниокР }}-$ расходы на НИОКР;

$$
R I M=\frac{C_{\text {НиоКР }}}{R}
$$

$R$ - выручка от продаж выработанной электроэнергии.

Четвертый показатель - доля затрат на социальную деятельность $(S)$ :

$$
S=\frac{C_{c o u}}{R},
$$

где $\quad C_{c o u}$ - расходы на социальную деятельность;

$R$ - выручка от продаж выработанной электроэнергии.

Разработанный раздел сбалансированной системы показателей АО «Концерн Росэнергоатом» может быть использован для мониторинга эффективности деятельности компании, планирования, контроллинга, обеспечения устойчивого роста и экономической безопасности предприятия в целом.

\section{Ссылки:}

1. Экономическая безопасность России. Общий курс : учебник / под ред. В.К. Сенчагова. 2-е изд. М., 2005. С. 744-745.

2. Kaplan R.S., Norton D.P. The balanced scorecard: translating strategy into action. Boston, 1996. 329 p.

3. Максимов А.А. Классификация рисков АО «Концерн Росэнергоатом» // Общество: политика, экономика, право. 2017. № 1. С. 84-86.

4. Стандарты безопасности. Возможности бизнеса [Электронный ресурс] : годовой отчет АО «Концерн Росэнергоатом» за 2015 r. URL: http://www.rosenergoatom.ru/resources/cd4d37004d4cab5ca0faa16b99a98da8/Rea_2015_Report_RUS.pdf (дата обращения: 04.02.2017).

\section{References:}

Kaplan, RS \& Norton, DP 1996, The balanced scorecard: translating strategy into action, Boston, $329 \mathrm{p}$.

Maksimov, AA 2017, 'Risk classification of "Rosenergoatom Concern" OJSC', Obshchestvo: politika, ekonomika, pravo, no. 1, pp. 84-86, https://doi.org/10.24158/pep.2017.1.21.

Senchagov, VK (ed.) 2005, Economic security of Russia. General course, textbook, 2nd ed., Moscow, pp. 744-745, (in Russian). 